\begin{tabular}{|l|l|l|l|l|l|} 
J. Tek. Ling & Vol.11 & No.2 & Hal. 167 - 173 & Jakarta, Mei 2010 & ISSN 1441-318X \\
\hline
\end{tabular}

\title{
JAMUR PEMBENTUK GAHARU SEBAGAI PENJAGA KELANGSUNGAN HIDUP TANAMAN GAHARU (Aquilaria sp)
}

\author{
Yohanes Bernard Subowo \\ Peneliti di Bidang Mikrobiologi, Puslit Biologi-LIPI \\ E-mail: yosubowo@yahoo.com
}

\begin{abstract}
Agarwood is economical important non forest timber product. The objective of this research was to obtain fungi that have ability to effectively infect and form agarwood. The fungi were isolated and selected from agarwood for effective infection studies. Ten isolates were successfully isolated, they were belonging to Aspergillus (JG5, JG17, KT17, JG31, JG32, JG21, JG19), Penicillium (JG4), Fusarium (JG12, JG18). Four isolates were successful form effective infection and they identified as Aspergillus $s p$ JG17, Aspergillus sp JG31, Aspergillus sp JG32 and Fusarium sp JG12. They produced secondary metabolite. The Fusarium sp JG12 was the most effective strain produced agarwood and form resin gaharu on Aquilaria beccariana after 4 months inoculation. The size of agarwood formed was $2,96 \mathrm{~cm}$ in length and $0,16 \mathrm{~cm}$ wide. It is recommended to use this strain for effective formation of agarwood.
\end{abstract}

Key words: isolation, fungi, agarwood, Fusarium

\section{PENDAHULUAN}

Hutan Indonesia yang memiliki luas 138 juta hektar ${ }^{1)}$ menghasilkan berbagai macam komoditi. Salah satunya yang memiliki nilai ekonomi tinggi adalah gaharu. Gaharu adalah sejenis kayu dengan berbagai bentuk dan warna yang khas, serta memiliki kandungan damar wangi, berasal dari pohon atau bagian pohon penghasil gaharu yang tumbuh secara alami dan telah mati, sebagai akibat dari proses infeksi yang terjadi baik secara alami atau buatan pada pohon tersebut dan pada umumnya terjadi pada pohon Aquilaria sp (Nama daerah: Karas, Alim, Garu dan lain-lain)2).

Gaharu dihasilkan oleh tanaman penghasil gaharu yang terinfeksi penyakit. Ada beberapa jenis tanaman yang diketahui dapat menghasilkan gaharu, diantaranya Famili Thymeleaceae, Euforbiaceae dan Leguminoceae ${ }^{3)}$. Tanaman gaharu banyak tumbuh di daerah tropis, diantaranya marga Aquilaria, Gyrinops dan Gonystilus yang ketiganya termasuk Famili Thymelaeaceae. Enam jenis dari marga Aquilaria ditemukan di Indonesia, yaitu: $A$. malaccensis, $A$. microcarpa, A. hirta, A. beccariana, A. cumingiana dan $A$. filarial. Marga Gyrinops memiliki tujuh species, enam diantaranya tersebar di Indonesia bagian Timur serta satu species di Srilanka4).

Gaharu (gubal gaharu) dapat terbentuk secara alam yaitu bila terdapat luka pada batang kemudian terinfeksi oleh jamur penyakit. Menurut ${ }^{5)}$ terbentuknya gaharu 
secara alami berkaitan dengan proses patologis yang disebabkan beberapa jenis mikroba patogen pembentuk gaharu. Luka yang terjadi pada batang, cabang maupun ranting tanaman gaharu (Aquilaria sp) menyebabkan pohon terinfeksi oleh penyakit (bakteri, jamur atau virus) yang diduga mengubah pentosan atau selulosa pada kayu menjadi resin atau damar yang merupakan campuran sesquiterpena, dienona dan isopropanoid. Resin dan damar terkumpul di dalam rongga sel yang dikenal sebagai gaharu6).

Penduduk pedalaman di Kalimantan Timur sudah tidak asing lagi dengan bisnis gaharu. Mereka mendapatkan gaharu dari hutan dengan cara menebang pohon gaharu. Kadangkala gaharu yang diharapkan tidak diperoleh namun pohon sudah terlanjur ditebang. Hal ini tentunya akan membahayakan populasi tanaman gaharu (Aquilaria sp). Dengan berkembangnya teknik inokulasi menggunakan jamur pembentuk gaharu, maka kepunahan tanaman gaharu dapat dicegah. Inokulasi jamur dapat diatur pada cabang-cabang pohon, sehingga hasil gaharu dapat diperoleh tanpa harus menebang pohon gaharu.

Beberapa jamur Ascomycetes dapat menginfeksi batang tanaman gaharu sehingga menghasilkan gubal gaharu. ${ }^{7)}$ berhasil mengisolasi beberapa jamur dari pohon Aquilaria spp yang terinfeksi, yaitu: Fusarium oxysporium, Fusarium bulbigenium dan Fusarium laseritium. Menurut $\left.{ }^{8}\right)$ gubal gaharu diduga dapat terbentuk melalui infeksi cendawan. Pembentukan gubal gaharu di alam tentunya melibatkan beberapa jenis jamur. Namun sejauh ini informasi mengenai keberadaan jamur-jamur Ascomycetes pada gubal gaharu yang mampu membentuk damar gaharu masih sedikit. Oleh karena itu dilakukan isolasi dan seleksi jamur-jamur yang mampu membentuk gubal gaharu. Adapun tujuan penelitian ini adalah untuk memperoleh isolat jamur yang mampu menginfeksi tanaman gaharu serta memperoleh isolat jamur yang paling efektif menghasilkan gubal gaharu

\section{METODOLOGI}

\subsection{Bahan}

Bahan dan alat yang digunakan meliputi: gubal gaharu, batang gaharu yang terinfeksi jamur, media Taoge Agar, serbuk kayu gaharu, tepung jagung, pohon gaharu yang tumbuh di alam. Alkohol 95\%, pinset, kapas, bor listrik, mata bor ukuran $10 \mathrm{~mm}$, genset portabel, lilin mainan, label seng, paku, spidol, alat suntik ukuran $1 \mathrm{ml}$, penggaris, cuter dan meteran.

\subsection{Isolasi}

Gubal gaharu atau kayu gaharu yang terinfeksi dipotong kecil-kecil, kemudian potongan-potongan diletakkan pada permukaan media Taoge Agar dalam petridish, dan kultur diinkubasi selama 3 hari. Setelah 3 hari jamur pada potongan gubal atau kayu gaharu akan tumbuh pada permukaan media, kemudian miselium jamur ini dipindahkan pada media baru sampai diperoleh isolat murni (hanya satu jenis jamur). Setelah murni isolat jamur dipindahkan ke media agar miring pada test tube.

\subsection{Pertumbuhan jamur pada serbuk kayu gaharu}

Serbuk kayu gaharu diayak untuk memisahkan bagian kasar dan halus, setelah itu serbuk yang halus dicampur dengan tepung jagung sebanyak $10 \%$, ditambah air sampai cukup basah kemudian dimasukkan botol dan diberi sumbat kapas. Botol dan media disterilisasi di dalam otoclaf. Isolat jamur ditumbuhkan pada media Taoge Agar, setelah tumbuh kemudian dipindahkan pada media serbuk gaharu. Kultur diinkubasi pada suhu ruang sambil diamati pertumbuhan miseliumnya.

\subsection{Pertumbuhan jamur pada batang tanaman Gaharu}

Batang gaharu yang ada di alam dibersihkan sekelilingnya, pohon dibersihkan dengan alkohol 95\%. Kemudian batang dilubangi menggunakan bor; diameter mata 
bor $10 \mathrm{~mm}$ dengan kedalaman $7 \mathrm{~cm}$. Lubang pada pohon diisi dengan miselium jamur hasil isolasi menggunakan sendok timbang dan pinset, setiap lubang diisi sampai penuh. Kemudian lubang ditutup menggunakan lilin mainan.

\subsection{Pemeriksaan jaringan kayu secara mikroskopis}

Gubal gaharu yang terbentuk pada batang gaharu, dipotong, kemudian dimasukkan alkohol. Batang atau potongan ranting difiksasi, dipotong menggunakan pisau mikrotom. Kemudian pita berisi potongan batang ditempelkan pada objek glass dan diamati dibawah mikroskop.

\subsection{Pengamatan pembentukan gubal pada tanaman gaharu}

Pengamatan pembentukan gubal gaharu dilakukan setelah empat bulan infeksi, yaitu dengan membuka kulit kayu disekitar lubang inokulasi. Warna coklat sampai hitam yang terbentuk di sekitar lubang inokulasi merupakan gubal gaharu yang terbentuk akibat infeksi jamur. Warna coklat yang terbentuk diukur panjang dan lebarnya. Bau wangi gaharu juga diamati dengan membakar sedikit gubal yang terbentuk, bila bau wangi gaharu tercium maka proses pembentukan gubal gaharu sedang terjadi.

\section{HASIL DAN PEMBAHASAN}

\subsection{HASIL}

Isolasi jamur gaharu dilakukan dari gubal gaharu dan batang gaharu yang terinfeksi jamur. Gubal dan batang gaharu diperoleh dari petani gaharu di Kabupaten Malinau, Kalimantan Timur. Dari kegiatan ini diperoleh 10 isolat jamur yang termasuk dalam 3 marga, yaitu: Aspergillus, Penicillium dan Fusarium (Tabel 1).
Tabel1. Hasil isolasi jamur gaharu

\begin{tabular}{|c|l|l|l|}
\hline No & $\begin{array}{l}\text { Kode } \\
\text { Isolat }\end{array}$ & \multicolumn{1}{|c|}{ Sumber } & Nama Jamur \\
\hline 1 & JG 5 & Gubal gaharu & Aspergillus $\mathrm{sp}$ \\
\hline 2 & KT 17 & Gubal gaharu & Aspergillus $\mathrm{sp}$ \\
\hline 3 & JG 17 & Gubal gaharu & Aspergillus $\mathrm{sp}$ \\
\hline 4 & JG 32 & Gubal gaharu & Aspergillus $\mathrm{sp}$ \\
\hline 5 & JG 4 & Kayu terinfeksi & Penicillium $\mathrm{sp}$ \\
\hline 6 & JG 21 & Gubal gaharu & Aspergillus $\mathrm{sp}$ \\
\hline 7 & JG 12 & Gubal gaharu & Fusarium $\mathrm{sp}$ \\
\hline 8 & JG 18 & Gubal gaharu & Fusarium $\mathrm{sp}$ \\
\hline 9 & JG 31 & Kayu terinfeksi & Aspergillus $\mathrm{sp}$ \\
\hline 10 & JG 19 & Kayu terinfeksi & Aspergillus $\mathrm{sp}$ \\
\hline
\end{tabular}

Selanjutnya isolat jamur ditumbuhkan pada media serbuk kayu gaharu, untuk melihat kemampuan tumbuh masing-masing isolat. Hasilnya menunjukkan bahwa semua isolat dapat tumbuh pada media serbuk kayu gaharu (Tabel 2).

\begin{tabular}{|c|c|l|c|}
\hline No & $\begin{array}{c}\text { Kode } \\
\text { Isolat }\end{array}$ & Jenis jamur & Pertumbuhan \\
\hline 1 & JG 5 & Aspergillus sp & + \\
\hline 2 & KT 17 & Aspergillus sp & + \\
\hline 3 & JG 17 & Aspergillus sp & + \\
\hline 4 & JG 32 & Aspergillus sp & + \\
\hline 5 & JG 4 & Penicillium $\mathrm{sp}$ & + \\
\hline 6 & JG 21 & Aspergillus $\mathrm{sp}$ & + \\
\hline 7 & JG 12 & Fusarium $\mathrm{sp}$ & + \\
\hline 8 & JG 18 & Fusarium $\mathrm{sp}$ & + \\
\hline 9 & JG 31 & Aspergillus $\mathrm{sp}$ & + \\
\hline 10 & JG 19 & Aspergillus $\mathrm{sp}$ & + \\
\hline
\end{tabular}

Keterangan:

+ : tumbuh $\quad-$ : tidak tumbuh

Isolat jamur kemudian ditumbuhkan pada batang tanaman gaharu untuk melihat kemampuan tumbuh masing-masing jamur. Ternyata tidak semua isolat jamur mampu tumbuh pada batang tanaman gaharu yang masih hidup. Jamur yang mampu tumbuh pada Girinops sp adalah Aspergillus sp JG17, Aspergillus sp JG32, Fusarium sp JG12, Fusarium sp JG18, Aspergillus sp JG31. Sedangkan pada tanaman Aquilaria malacensis: Aspergillus sp KT17, Aspergillus 
sp JG32, Fusarium sp JG12, dan Fusarium sp JG18 (Tabel 3).

Tabel 3. Pertumbuhan isolat jamur pada batang tanaman gaharu

\begin{tabular}{|c|c|c|c|}
\hline No & $\begin{array}{c}\text { Kode } \\
\text { Isolat }\end{array}$ & $\begin{array}{c}\text { Pertumbuhan } \\
\text { pada } \\
\text { Girinops sp }\end{array}$ & $\begin{array}{c}\text { Pertumbuhan } \\
\text { pada } \\
\text { A. malacensis }\end{array}$ \\
\hline 1 & JG 5 & - & - \\
\hline 2 & KT 17 & - & + \\
\hline 3 & JG 17 & + & - \\
\hline 4 & JG 32 & + & + \\
\hline 5 & JG 4 & - & - \\
\hline 6 & JG 21 & - & - \\
\hline 7 & JG 12 & + & + \\
\hline 8 & JG 18 & + & + \\
\hline 9 & JG 31 & + & - \\
\hline 10 & JG 19 & - & - \\
\hline
\end{tabular}

Keterangan:

$$
+ \text { : tumbuh } \quad-\quad \text { : tidak tumbuh }
$$

Setelah dilakukan pemotongan jaringan batang secara melintang, pada bagian tengan batang sel-selnya terisi oleh damar gaharu berwarna coklat. Hal ini terjadi pada perlakuan jamur Fusarium sp JG12, Aspergillus sp JG17, Aspergillus JG31 dan Aspergillus sp JG32 (Gambar 1).

Gambar 1.A.Jaringan batang gaharu sehat. B. Jaringan batang gaharu yang terisi damar/ minyak gaharu C. Batang gaharu yang diinfeksi Fusarium sp JG12. D. Batang gaharu yang diinfeksi Aspergillus sp JG 17 E. Batang gaharu yang diinfeksi Aspergillus sp JG 31. F. Batang gaharu yang diinfeksi Aspergillus sp JG 32

Setelah diinfeksikan pada batang tanaman gaharu ( $A$. beccariana) yang tumbuh di alam, keempat jamur dapat membentuk gubal gaharu. Ukuran gubal yang dibentuk berbeda antara jamur satu dengan lainnya. Gubal yang paling besar dibentuk oleh Fusarium sp JG12 dengan panjang 2,96 cm, kemudian Aspergillus sp JG31, Aspergillus sp JG32 dan terakhir Aspergillus sp JG17 (Tabel 4).

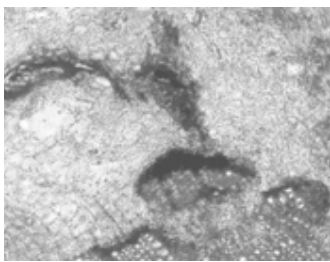

E

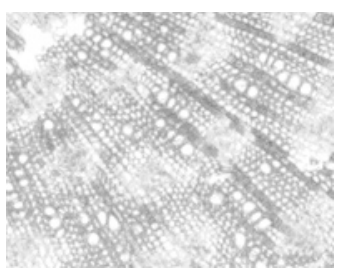

A

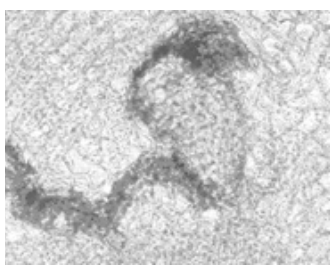

C

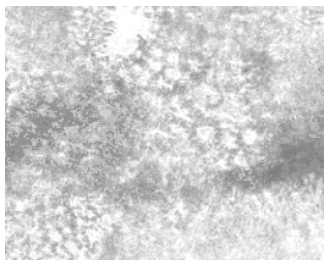

F

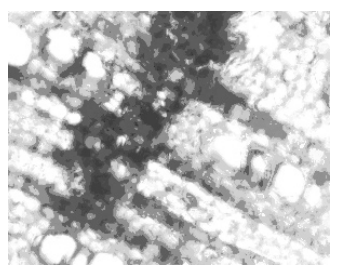

B

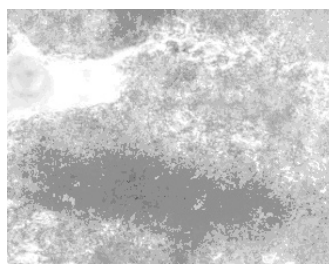

D

\subsection{PEMBAHASAN}

Gubal gaharu terbentuk akibat infeksi jamur patogen pada tanaman gaharu. Setelah dilakukan isolasi jamur pada gubal gaharu dan batang tanaman gaharu yang terinfeksi diperoleh 10 nomor isolat, yang termasuk dalam 3 marga, yaitu: Aspergillus, Penicillium dan Fusarium. Marga Aspergillus terdiri 7 jenis, Penicillium 1 jenis dan Fusarium 2 jenis. Jamur Fusarium sebagian besar anggotanya tergolong jamur penyakit tanaman, sedangkan jamur Aspergillus dan Penicillium sebagian besar anggotanya tergolong bukan jamur penyakit. Hal ini sejalan dengan penelitian sebelumnya yang menyatakan bahwa secara alami pohon Aquilaria diinfeksi oleh beberapa jamur meliputi: Aspergillus spp, Botryodyplodia spp, Diplodia spp, Fusarium bulbiferum, Fusarium laterium, F. Oxysporum, F. Solani, Penicillium spp dan Pythium spp ${ }^{9,10)}$ berhasil mengisolasi jamur Fusarium spp dari tanaman Aquilaria sinensis, selain itu juga diperoleh Penicillium sp. 
Tabel 4. Pembentukan gubal gaharu pada A. beccariana setelah 4 bulan infeksi

\begin{tabular}{|l|l|l|l|l|l|}
\hline No & \multicolumn{1}{|c|}{ Jamur } & $\begin{array}{c}\text { Panjang } \\
(\mathbf{c m})\end{array}$ & $\begin{array}{c}\text { Lebar } \\
(\mathbf{c m})\end{array}$ & Aroma & Warna \\
\hline 1 & $\begin{array}{l}\text { Aspergillus } \\
\text { sp JG31 }\end{array}$ & 2,96 & 0,33 & + & coklat \\
\hline & & 2,3 & 0,24 & + & coklat \\
\hline & & 2,9 & 0,5 & + & coklat \\
\hline & Rata-rata & $2,72 \mathrm{a}$ & $0,35 \mathrm{~b}$ & & \\
\hline 2 & $\begin{array}{l}\text { Fusarium } \\
\text { sp JG12 }\end{array}$ & 4,9 & 0,2 & + & $\begin{array}{l}\text { Coklat } \\
\text {-hitam }\end{array}$ \\
\hline & & 1,7 & 0,1 & + & $\begin{array}{l}\text { Coklat } \\
\text {-hitam }\end{array}$ \\
\hline & & 2,3 & 0,2 & + & $\begin{array}{l}\text { Coklat- } \\
\text { hitam }\end{array}$ \\
\hline & Rata-rata & $2,96 \mathrm{a}$ & $0,16 \mathrm{~b}$ & & \\
\hline 3 & $\begin{array}{l}\text { Aspergillus } \\
\text { sp JG17 }\end{array}$ & 2,3 & 0,2 & + & $\begin{array}{l}\text { Coklat } \\
\text { terang }\end{array}$ \\
\hline & & 2,1 & 0,5 & + & $\begin{array}{l}\text { Coklat } \\
\text { terang }\end{array}$ \\
\hline & & 2,1 & 0.2 & + & $\begin{array}{l}\text { Coklat } \\
\text { terang }\end{array}$ \\
\hline & Rata-rata & $2,16 \mathrm{a}$ & $0,3 \mathrm{~b}$ & & \\
\hline 4 & $\begin{array}{l}\text { Aspergillus } \\
\text { sp JG32 }\end{array}$ & 2,6 & 0,3 & + & coklat \\
\hline & & 2,1 & 0,2 & + & coklat \\
\hline & & 2,1 & 0,3 & + & coklat \\
\hline & Rata-rata & $2,26 \mathrm{a}$ & $0,26 \mathrm{~b}$ & & \\
\hline & & & & & \\
\hline
\end{tabular}

Keterangan: Angka-angka yang diikuti huruf yang sama tidak beda nyata pada taraf uji $5 \%$.

$+=$ mengeluarkan aroma gaharu setelah dibakar

- = tidak mengeluarkan aroma gaharu setelah Dibakar

Sepuluh isolat jamur hasil isolasi kemudian ditumbuhkan pada media serbuk kayu gaharu. Isolat-isolat ini berasal dari gubal dan kayu gaharu sehingga bila ditumbuhkan kembali pada kayu gaharu kemungkinan besar akan tumbuh. Ternyata semua isolat dapat tumbuh pada media serbuk kayu gaharu. Hal ini menunjukkan bahwa semua isolat berasal dari gubal dan kayu gaharu yang diisolasi. Jamur Penicillium, Aspergillus dan Fusarium tumbuh pada gubal dan kayu gaharu. ${ }^{11)}$ berhasil mengisolasi beberapa jamur dari kayu Aquilaria agallocha yang terinfeksi meliputi: Penicillium citrinum, Aspergillus tamarii, Aspergillus spp, Fusarium solani,Botryodiplodia theobromae dan lainlain. ${ }^{12)}$ berhasil mengidentifikasi empat jenis jamur yang terdapat pada biji Aquilaria agallocha yaitu: Aspergillus sp, Fusarium sp, Penicillium sp dan Epicoccum $\mathrm{sp}$.

Isolat-isolat jamur di atas kemudian diinfeksikan pada batang tanaman gaharu. Hal ini untuk melihat kemampuan jamur menginfeksi tanaman gaharu serta pembentukan gubal gaharu. Lima jenis jamur dapat tumbuh pada Gyrinops sp, terbukti warna kayu berubah menjadi coklat. Lima jamur tersebut adalah Fusarium sp JG 12, Fusarium sp JG 18, Aspergillus sp JG 17, Aspergillus sp JG 31 dan Aspergillus sp JG 32. Lima jamur yang lain tidak mampu menginfeksi tanaman gaharu. Pada Aquilaria malacensis, empat jamur dapat tumbuh yaitu: Aspergillus sp KT17, Aspergillus sp JG32, Fusarium sp JG12 dan Fusarium sp JG18. Jamur Aspergillus dan Fusarium dapat membentuk gubal gaharu sedangkan Penicillium tidak mampu menginfeksi tanaman gaharu. ${ }^{13)}$ melaporkan bahwa Fusarium sp dapat menginfeksi batang tanaman Aquilaria microcarpa.

Pengamatan mikroskopis pada penampang lintang batang yang terinfeksi jamur dapat memperjelas kemampuan empat jamur (Fusarium sp JG12, Aspergillus sp JG17, Aspergillus sp JG31, Aspergillus sp JG32) dalam pembentukan damar gaharu. Pada gambar $1 \mathrm{~A}$ nampak sel-sel penyusun batang bersih tidak terisi damar. Gambar ini diambil dari batang gaharu yang sehat (kontrol 1). Kemudian pada gambar $1 \mathrm{~B}$ nampak selsel penyusun batang sudah terisi oleh damar gaharu berwarna coklat. Gambar ini diambil dari batang gaharu yang terinfeksi jamur (kontrol 2). Pada gambar 1C nampak sel-sel penyusun batang bagian tengah sudah terisi damar gaharu berwarna coklat dan bagian tepi masih bersih. Gambar ini diambil dari batang gaharu yang diinfeksi jamur Fusarium sp JG12. Pada gambar 1D, 1E dan 1F nampak sel-sel 
penyusun batang gaharu bagian tengah terisi damar gaharu berwarna coklat. Gambar ini diambil dari batang gaharu yang diinfeksi oleh jamur Aspergillus sp JG17, Aspergillus sp JG31 dan Aspergillus sp JG32. Dari bukti gambar di atas semakin memperjelas bahwa ke empat jamur yang diuji mampu membentuk gubal gaharu. ${ }^{13)}$ melakukan infeksi jamur Chaetomium globosum dan Fusarium oxysporum pada $A$. agallocha Roxb. Setelah 30 hari tanaman menghasilkan minyak yang mengandung asam dodekanoat, asam pentadekanoat, asam heksadekanoat, dan asam oktadekanoat. Ditambah 2 senyawa yang tidak dijumpai pada minyak yang dihasilkan oleh tanaman sehat, yaitu: 10-epi- $\gamma$ eudesmol dan $\gamma$-eudesmol. ${ }^{13)}$ juga melaporkan bahwa tanaman $A$. microcarpa yang diinfeksi dengan Fusarium sp menghasilkan damar gaharu yang mengandung konstituen gaharu (komponen aromatis dan komponen aromatis yang merupakan pyrolisis dari bagian kayu) dan beberapa senyawa odorant yang digunakan dalam industri perfumery dan flavoring.

Empat jamur yang mampu membentuk gubal gaharu di atas, kemudian diinokulasikan pada tanaman $A$. beccariana yang sudah berumur puluhan tahun. Keempat jamur dapat membentuk gubal gaharu dengan ukuran yang berbeda antara satu dengan yang lainnya. Panjang area infeksi terbesar dihasilkan oleh jamur Fusarium sp JG12, yaitu 2,96 cm, kemudian Aspergillus sp JG31, Aspergillus sp JG32 dan terkecil Aspergillus sp JG17. Panjang pendeknya area infeksi ditentukan oleh kemampuan virulensi masing-masing jamur. Dengan kata lain jamur Fusarium sp memiliki tingkat virulensi yang lebih tinggi dibandingkan Aspergillus sp. Lebar area infeksi antar keempat jamur tidak berbeda nyata. Bila dibandingkan antara panjang dan lebar area terinfeksi, maka panjang area terinfeksi akan lebih besar. Hal ini berhubungan dengan arah pertumbuhan sel batang, yaitu ke arah vertikal. Pertambahan panjang sel akan lebih besar dibandingkan pertambahan lebarnya, sehingga pertumbuhan batang tanaman ke atas lebih besar dari pada ke arah samping. Akibatnya deposit resin gaharu lebih banyak ke arah vertikal (atas-bawah) dari pada ke arah horisontal (ke samping). Hasil ini masih lebih besar bila dibandingkan penelitian ${ }^{13)}$ yang menginfeksi $A$. microcarpa menggunakan jamur Fusarium sp. Setelah 6 bulan, panjang area infeksi 2,09 cm. Demikian pula bila dibandingkan hasil penelitian ${ }^{14}$ yang menginfeksi $A$. beccariana menggunakan jamur Fusarium solani M2B. Setelah empat bulan, panjang area infeksi $2,88 \mathrm{~cm}$.

Aroma wangi gaharu terbentuk oleh adanya resin yang merupakan metabolit sekunder yang dihasilkan tanaman gaharu untuk merespon infeksi jamur patogen. Menurut ${ }^{15)}$ metabolit sekunder pada kayu dapat disebut sebagai zat ekstraktif. Zat ini terdiri dari bermacam-macam senyawa yang memiliki fungsi sebagai daya tahan terhadap serangan jamur dan serangga, memberi bau, rasa dan warna kayu. ${ }^{13)}$ melaporkan bahwa resin gaharu hasil inokulasi mengandung eugenol, koniferil alkohol, guaiacol, katekol dan veratrol. Eugenol dan isoeugenol digunakan dalam memproduksi vanillin yang merupakan bahan penting dalam industri wewangian ${ }^{16}$.

Pembentukan gubal gaharu disertai dengan adanya perubahan warna jaringan kayu dari putih menjadi coklat bahkan warna hitam. Warna ini disebabkan oleh adanya resin gaharu yang terakumulasi dalam rongga sel. Semakin lama resin yang terakumulasi semakin banyak dan warna kayu akan menjadi coklat kehitaman. Menurut ${ }^{17)}$ luka pada batang akibat pengeboran dapat merangsang sistim pertahanan tanaman dimana pada akhirnya akan menyebabkan tanaman memproduksi metabolit sekunder sejenis sesquiterpenoid.

\section{KESIMPULAN}

Jamur Fusarium sp JG12, Aspergillus sp JG17, Aspergillus sp JG31 dan Aspergillus sp JG32 mempunyai kemampuan menginfeksi tanaman Aquilaria beccariana dan Gyrinops sp membentuk gubal gaharu 
Jamur Fusarium sp JG12 membentuk area infeksi paling besar pada Aquilaria beccariana dengan panjang 2,96 cm dalam waktu 4 bulan setelah infeksi

\section{DAFTAR PUSTAKA}

1. Media Indonesia, 16 Juni 2009. Luas hutan di Indonesia 138 hektare. http:// www.mediaindonesia.com/

2. Anonim. 1999. Gaharu Standar Nasional Indonesia 01-5009.11999, 6pp.

3. Sumarna .Y. 2007. Budidaya Gaharu. Penebar Swadaya, Jakarta, 80 pp.

4. Anonim. 2009. Gaharu: HHBK yang menjadi Primadona

5. Hartal dan G. Anwar. 2007. Teknologi Peningkatan Kualitas Kayu Gubal Gaharu (Aquilaria malacensis Lamk) di Kawasan Pesisir Bengkulu dengan Inokulasi jamur penginduksi resin. Jurnal IImu-ilmu Pertanian Indonesia, No 3: 464-471.

6. Hasbullah F. 2008. Panduan cara penyuntikan gaharu teknik spiral. http:// gaharubertuah.indonetwork.net/.

7. Santoso. E. 1996. Pembentukan gaharu dengan dengan cara inokulasi.Makalah Diskusi hasil penelitian dalam menunjang pemanfaatan hutan yang lestari. Bogor, 11-12 Maret 1996. Pusat Litbang Hutan dan Konservasi Alam, 3 pp.

8. Nobuchi T and S. Siripatanadilok. 1991. Preliminary observation of Aquilaria crassna wood associated with the formation of aloeswood. Bulletin Kyoto University Forest, 63: 226-235.

9. Akter N and A. Neelin. 2008. Agarwood plantation at BRAC Tea Estate: Introduction, Environmental Factor and Financial Analysis. BRAC Centre, Bangladesh.

10. Gong L.J and SX. Guo. 2009. Endophytic fungi from Dracaena cambodiana and Aquilaria sinensis and their antimicrobial activity. African Journal of Biotechnology, 8 (5): 731-736.
11. Gibson. I. 1977. The Role of Fungi in the Origin of Oleoresin Deposits (Agaru) in the wood of Aquilaria agallocha Roxb. Bano Biggyan Patrika, 6 (1): 16-26.

12. Novriyanti E. 2009. Kajian kimia gaharu hasil inokulasi Fusarium sp pada Aquilaria microcarpa. Workshop Pengembangan Teknologi Produksi Gaharu berbasis Pada Pemberdayaan Masyarakat di Sekitar Hutan. Bogor, 29 April 2009, 17 pp.

13. Tamuli, Phatik, Boruah, Paran, Nath, Subhan C, Leclercq, Piet. 2005. Essential oil of eaglewood Tree: a Product of Pathogenesis. Journal of Essential Oil Research, Nov/ Dec 2005, $4 \mathrm{pp}$.

14. Subowo YB dan A. Wawo. 2010. Inokulasi beberapa jamur Fusarium solani pada batang tanaman gaharu (Aquilaria sp) di Kabupaten Malinau, Kalimantan Timur. Prosiding Seminar Nasional Basic Science, Malang 20 Februari 2010, pp: 348-352.

15. Santoso E, RSB. Irianto, M. Turjaman, IR. Sitepu, S.Santoso, Najmulah, A. Yani dan Aryanto. 2009. Teknologi Induksi pohon penghasil gaharu. Workshop Pengembangan Teknologi Produksi Gaharu berbasis Pada Pemberdayaan Masyarakat di Sekitar Hutan. Bogor, 29 April 2009, 14 pp.

16. Cowan M. 1999. Plant Products as Antimicrobial Agents. Clinical Microbiology Review, 12 (4): 564-582.

17. Umboh M.I.J. 2005. Pentingnya konservasi Pohon Gaharu dan Upaya Peningkatan Produksinya. Lembaga Penelitian Universitas Negeri Manado. Prosiding Seminar Nasional Gaharu, Bogor, 1-2 Desember 2005. 